\title{
Efeitos Alelopáticos do Calopogônio em Função de sua IdAde e da Densidade de Sementes da Planta Receptora ${ }^{1}$
}

\author{
Allelopathic Effects of Calopo According to its Age and to Seed Density of the Receiver Plant
}

SOUZA FILHO, A.P.S. ${ }^{2}$, ALVES, S.M. ${ }^{2}$ e FIGUEIREDO, F.J.C. ${ }^{2}$

\begin{abstract}
RESUMO - A intensidade dos efeitos potencialmente alelopáticos depende de fatores relacionados à espécie doadora e receptora. Neste trabalho, analisaram-se as variações nos efeitos alelopáticos do calopogônio (Calopogonium mucunoides) em função de sua idade (2, 4, $6,8,10$ e 12 semanas após a emergência) e da densidade de sementes da espécie receptora $\left(500,1.000,2.000,3.000\right.$ e 4.000 sementes $\left.\mathrm{m}^{-2}\right)$. Em cada idade, as plantas foram coletadas e separadas em parte aérea e raízes. Os efeitos alelopáticos foram avaliados sobre a germinação das sementes das plantas daninhas: Mimosa pudica (malícia), Urena lobata (malva), Senna obtusifolia (mata-pasto) e Senna occidentalis (fedegoso). A intensidade dos efeitos alelopáticos variou negativamente em função do aumento da densidade de sementes das espécies daninhas. Essa variação foi mais intensa nas espécies com sementes grandes, como malva e matapasto, do que naquelas de sementes pequenas, como malícia e fedegoso. A idade da planta foi fator determinante nos efeitos alelopáticos do calopogônio. Aparentemente, a planta aloca suas substâncias químicas com atividade alelopática de forma diferenciada nas raízes e na parte aérea. A parte aérea do calopogônio revelou intensidade de efeitos alelopáticos crescentes até a idade de quatro semanas, quando atingiu seu valor máximo. Já os efeitos promovidos pelas raízes foram crescentes com a idade até 12 semanas de crescimento, quando os efeitos superaram aqueles promovidos pela parte aérea. Esses resultados indicam que existe possibilidade de manejo da leguminosa forrageira calopogônio, visando maximizar a sua atividade potencialmente alelopática.
\end{abstract}

Palavras-chave: alelopatia, germinação, inibição, leguminosa, planta daninha.

\begin{abstract}
The intensity of the potential allelopathic effects depends on factors either related to the donor or receiver species. This research analyzes the variations on the allelopathic effect intensities of calopo (Calopogonium mucunoides) in relation to age of the donor plants (2, 4, 6, 8, 10 and 12 weeks after emergence) and to seed density of the receiver species (500, 1,000, 2,000, 3,000 and 4,000 seeds per $\mathrm{m}^{2}$ ). At each assigned age, plants were harvested and divided into shoot and root. The potential allelopathic effects were determined on the germination rates of the following weed seeds: Mimosa pudica, Urena lobata, Senna obtusifolia and Senna occidentalis. The intensity of the allelopathic effects was inversely related to the seed density increase. The effect was more intense for large-seeded (Urena lobata and Senna obtusifolia) than for small-seeded species (Mimosa pudica and Senna occidentalisfedegoso). Age was very important for the allelopathic effects of calopo. Calopo shoots showed increasing allelopathic effects with age, showing maximum effects at the age of four weeks. For roots, those effects increased until plants were 12 weeks old, when the values were higher than those observed for shoots. These results suggest that the forage legume calopo could be managed to maximize its allelopathic potential.
\end{abstract}

Key words: allelopathy, germination, inhibition, legume, weeds.

Recebido para publicação em 1.3.2002 e na forma revisada em 11.8.2003.

Embrapa Amazônia Oriental, Trav. Dr. Enéas Pinheiro, S/N, 66095-100 Belém-PA, <apedro@cpatu.embrapa.br>. 


\section{INTRODUÇÃO}

As plantas produzem e estocam grande número de produtos do seu metabolismo, os quais são posteriormente liberados para o ambiente de diferentes formas, como volatilização, exsudação radicular, lixiviação de partes das plantas vivas e mortas e decomposição de resíduos (Putnam, 1983; Rice, 1987). Embora pouco se saiba com exatidão como esses produtos são formados nas células, sabese que eles têm suas sínteses a partir da rota do acetato e/ou ácido chiquímico (Einhellig, 1995). A via do acetato propicia a produção de uma variedade de ácidos orgânicos, álcoois de cadeia linear, aldeídos e cetonas, muitos dos quais reconhecidos entre os aleloquímicos voláteis liberados durante a decomposição de resíduos (Bradow \& Connick, 1990). A via do ácido chiquímico conduz a uma variedade de taninos hidrolisáveis, ácido gálico e outros. Os terpenóides têm suas biossinteses originadas através do mevalonato e são o maior grupo de substâncias químicas das plantas (Langenheim, 1994).

Conquanto muito se tenha avançado em relação ao entendimento dos aspectos básicos que regem o fenômeno alelopatia, pouco se sabe a respeito dos mecanismos que regulam o padrão de produção e de distribuição dos aleloquímicos na planta, bem como sobre os fatores que interferem nos resultados. As informações disponíveis mostram que substâncias químicas com atividade alelopática estão presentes em todos os órgãos das plantas, como folhas, rizomas, sementes e raízes, entre outros (Putnam \& DeFrank, 1981; Friedmam \& Waller, 1983; Smith \& Martin, 1994; Souza Filho et al., 1997a). Entretanto, a distribuição das substâncias não é uniforme, havendo variações em função da espécie e do órgão da planta analisado (Hedge \& Miller, 1990; Rao, 1990). Com relação às variações na alocação dessas substâncias, na parte aérea e nas raízes, em função da idade de crescimento, elas ainda não foram analisadas. Wardle (1987) sugere que as plantas forrageiras são provavelmente alelopáticas apenas em certos estádios de seu ciclo. No entanto, estudos desenvolvidos com a gramínea forrageira Brachiaria brizantha cv. Marandu, envolvendo a análise das variações na atividade potencialmente alelopática em função do estádio de desenvolvimento das plantas, indicaram que a atividade alelopática nessas espécies é mais intensa quando as plantas estão na fase vegetativa (três meses de cultivo) do que quando na fase reprodutiva - início da floração (Souza Filho et al., 2000). Variações na atividade alelopática são, ainda, observadas em função da especificidade entre plantas doadora e receptora (Souza Filho, 1995), porém muito precisa ser elucidado com relação aos fatores que comandam esse aspecto.

Especificamente para Calopogonium mucunoides, as informações disponiveis mostram que essa leguminosa possui potencialidades alelopáticas e que a parte aérea, seguida das raízes, se constitui na principal fonte de substâncias químicas com atividades potencialmente alelopáticas, solúveis em água (Souza Filho et al., 1997b). O presente trabalho objetivou analisar as variações nos efeitos potencialmente alelopáticos da leguminosa forrageira Calopogonium mucunoides, em função da idade de coleta das frações raízes e parte aérea das plantas e da densidade de sementes de espécies de plantas receptoras.

\section{MATERIAL E MÉTODOS}

\section{Efeitos da densidade de sementes das espécies receptoras}

A leguminosa calopogônio (Calopogonium mucunoides) foi cultivada no Campo Experimental da Embrapa Amazônia Oriental, localizado no município de Belém, Estado do Pará. Ao final de um período de três meses, a parte aérea (folhas + colmos) foi cortada rente ao solo, seca em estufa com circulação de ar forçado a $39^{\circ} \mathrm{C}$, por 96 horas, e triturada em moinho tipo Willey. Posteriormente, retirou-se aliquota de 300 gramas e adicionaram-se 3,0 litros de água destilada. A solução permaneceu em infusão por oito horas, filtrando-se em seguida e liofilizando. O extrato aquoso foi preparado a partir do material liofilizado na concentração de 2,0\%. Foram consideradas cinco densidades de sementes das espécies receptoras: $500,1.000,2.000,3.000 \mathrm{e}$ 4.000 sementes $\mathrm{m}^{-2}$, correspondendo, respectivamente, a 13, 25, 50, 75 e 100 sementes/ placa de Petri transparente, de $9,0 \mathrm{~cm}$ de diâmetro. 


\section{Efeitos da idade de crescimento na atividade alelopática}

O calopogônio foi semeado no Campo Experimental da Embrapa Amazônia Oriental, localizado em Belém, Pará. Após a emergência, as plantas foram arrancadas nas idades de 2, 4, 6, 8, 10 e 12 semanas de crescimento. Para efeito de início de contagem, idade zero, considerou-se o momento em que as plântulas estavam com dois folíolos expandidos. Em cada idade de coleta, as plantas eram arrancadas e separadas em parte aérea (folhas + colmos) e raízes. O material foi seco em estufa com circulação forçada de ar a $39^{\circ} \mathrm{C}$, por 96 horas, e triturado em moinho tipo Willey. Em seguida, adicionou-se 1,0 litro de água para cada 500 gramas de material seco, deixando-se em infusão por oito horas, em temperatura ambiente, filtrando-se e liofilizando. O extrato aquoso foi preparado partindo-se do material liofilizado, na concentração de $2,0 \%$.

\section{Procedimentos experimentais}

A germinação foi monitorada em períodos de 15 dias, com contagens diárias e eliminação das sementes germinadas. Consideraram-se como germinadas as sementes que apresentavam extensão radicular de 2,00 mm (Juntila, 1976; Duram \& Tortosa, 1985). Todos os bioensaios foram desenvolvidos em condições controladas de $25{ }^{\circ} \mathrm{C}$ de temperatura constante e fotoperiodo de 12 horas. Especificamente para os bioensaios em que se avaliaram as variações na atividade potencialmente alelopática, em função da idade de crescimento, utilizaram-se 25 sementes por placa de Petri. A germinação foi avaliada considerando dois aspectos: Índice de Velocidade de Germinação - IVG e percentual de germinação. O IVG foi calculado tendo por base a equação:

$$
I V G=\left[N_{1} / 1+N_{2} / 2+N_{3} / 3+\ldots+N_{n} / n\right] \times 100
$$

em que $\mathrm{N}_{1}, \mathrm{~N}_{2}, \mathrm{~N}_{3}$ e $\mathrm{N}_{\mathrm{n}}$ correspondem à proporção de sementes germinadas no primeiro, segundo, terceiro e enésimo dias a partir da semeadura. Assim, o IVG pode variar de 0 (se nenhuma semente germinar) a 100 (se todas as sementes germinarem no primeiro dia) (Wardle et al., 1991).
Como plantas receptoras, foram utilizadas as principais plantas invasoras que freqüentemente infestam as pastagens cultivadas da região amazônica, que são: malícia (Mimosa pudica), malva (Urena lobata), mata-pasto (Senna obtusifolia) e fedegoso (Senna occidentalis. As sementes foram coletadas em áreas de pastagens cultivadas, em fazendas localizadas no município de Castanhal. Passaram por processo de limpeza e foram tratadas, com vistas à superação da dormência, conforme estipulado por Souza Filho et al. (1998).

Tanto no bioensaio em que se avaliaram os efeitos da densidade de sementes como naquele em que foram avaliados os efeitos da idade de crescimento, os extratos aquosos foram adicionados apenas uma vez, no início dos bioensaios, sendo adicionada, a partir de então, apenas água destilada, quando necessário. Cada placa de Petri de 9,0 cm de diâmetro recebeu $3,0 \mathrm{~mL}$ de extrato. Os efeitos inibitórios dos extratos foram analisados tendo como fator de comparação, tratamento testemunha, a água destilada.

O delineamento experimental para todos os bioensaios foi o inteiramente casualizado, com três repetições. Os dados foram analisados pelo teste $\mathrm{F}$ e as médias comparadas pelo teste de Tukey (5\%). Todas as análises foram feitas utilizando-se o SAS (Sas, 1989).

\section{RESULTADOS E DISCUSSÃO}

\section{Efeitos da densidade de sementes}

Independentemente da espécie receptora, o percentual de germinação esteve positivamente associado à densidade de sementes: quanto maior a densidade, maior o percentual de germinação. Esse resultado indica que o potencial inibitório do extrato decresceu em função do aumento da densidade, tanto quando se analisaram os efeitos sobre o percentual de germinação como quando se analisou o IVG. Entretanto, a maior ou menor interferência da densidade de sementes nos efeitos potencialmente alelopáticos esteve associada à espécie receptora. Para a espécie malva, o extrato foi efetivo na inibição da germinação (\%) apenas na densidade de 500 sementes $\mathrm{m}^{-2}$, enquanto para mata-pasto, em densidades iguais ou superiores a 2.000 sementes, os efeitos do

Planta Daninha, Viçosa-MG, v.21, n.2, p.211-218, 2003 
extrato foram inócuos ou de baixa magnitude. Já para a espécie malícia o efeito do extrato, na densidade de 500 sementes $\mathrm{m}^{-2}$, foi letal para a germinação (\%) das sementes. Em se tratando de densidades de 4.000 sementes, malícia foi a única espécie em que a germinação foi inibida pelo extrato. Para o fedegoso, a inibição na germinação (\%) foi observada até a densidade de 3.000 sementes $\mathrm{m}^{-2}$, embora, nesta densidade, os efeitos observados tenham sido de baixa magnitude (Tabela 1).

O IVG, ao contrário dos efeitos observados sobre o percentual de germinação, foi afetado em todas as densidades, embora as inibições tenham, à semelhança do observado para o percentual de germinação, decrescido com o aumento da densidade (Tabela 1). Esse resultado foi mais marcante na espécie malícia e menor para malva, que a partir da densidade de 1.000 sementes $\mathrm{m}^{2}$ não apresentou diferença $(p<0,05)$ no IVG, mostrando, assim, que este é um fator menos dependente da densidade do que o percentual de germinação.

Paralelamente, a análise do comportamento da germinação (percentual e IVG), em cada densidade, indicou que a sensibilidade aos efeitos potencialmente alelopáticos foi sempre na seguinte ordem decrescente: malícia $>$ fedegoso > mata-pasto > malva. Essa mesma seqüência é verificada quando se comparam os efeitos alelopáticos do extrato na germinação (percentual e IVG) em função do aumento da densidade. Esses resultados indicam que o fator espécie receptora teve papel preponderante, o que pode ser atribuído ao tamanho das sementes. Pesagens realizadas indicaram os seguintes pesos (média de 10 pesagens de 100 sementes cada): malva $=$ $1,73 \mathrm{~g}$; mata-pasto $=1,42 \mathrm{~g}$; fedegoso $=0,675 \mathrm{~g}$ e malícia $=0,41 \mathrm{~g}$. O conjunto dessas informações mostra que, quanto mais pesadas eram as sementes, menores os efeitos potencialmente alelopáticos dentro de uma mesma densidade e em função do aumento da densidade de sementes. Para densidades iguais ou superiores a 1.000 sementes $\mathrm{m}^{-2}$, efeitos potencialmente alelopáticos inibitórios da germinação (\%) não são observados para a espécie malva, que apresentou sementes de maior peso, enquanto para mata-pasto os efeitos foram de baixa magnitude a partir da densidade de 2.000 sementes $\mathrm{m}^{-2}$. No entanto, para espécies com sementes pequenas, como a malícia, que apresentou menor peso, mesmo em densidade de 4.000 sementes $\mathrm{m}^{-2}$, efeitos inibitório foram obtidos. Esses mesmos comportamentos foram observados para a espécie fedegoso, cujas sementes foram mais pesadas apenas que as sementes de malícia e onde inibições potencialmente alelopáticas foram observadas até a densidade de 3.000 sementes.

Considerando que para todas as densidades estudadas o volume de extrato adicionado por placa de Petri de $9,0 \mathrm{~cm}$ de diâmetro foi o mesmo $(3,0 \mathrm{~mL})$, as reduções nos efeitos potencialmente alelopáticos com o aumento da densidade de sementes, em função do tamanho das sementes, podem ser atribuídas à partição das substâncias químicas responsáveis pelas

Tabela 1 - Variações nos efeitos potencialmente alelopáticos de extratos aquosos preparados da parte aérea do calopogônio em função da densidade de sementes. Dados expressos em percentual de germinação das sementes

\begin{tabular}{|c|c|c|c|c|c|c|}
\hline \multirow{2}{*}{$\begin{array}{l}\text { Parâmetro } \\
\text { analisado }\end{array}$} & \multirow{2}{*}{$\begin{array}{l}\text { Espécie } \\
\text { receptora }\end{array}$} & \multicolumn{5}{|c|}{ Densidade de sementes $\mathrm{m}^{-2}$} \\
\hline & & 500 & 1000 & 2000 & 3000 & 4000 \\
\hline \multirow{4}{*}{ Germinação } & Mata-pasto & $53,0 \mathrm{Bd}$ & $65,0 \mathrm{Bc}$ & $83,0 \mathrm{Bb}$ & $95,0 \mathrm{Aa}$ & $96,0 \mathrm{Aa}$ \\
\hline & Malícia & $0,0 \mathrm{De}$ & $16,0 \mathrm{Dd}$ & $23,0 \mathrm{Dc}$ & $59,0 \mathrm{Cb}$ & $73,0 \mathrm{Ba}$ \\
\hline & Fedegoso & $37,0 \mathrm{Ce}$ & $54,0 \mathrm{Cd}$ & $69,0 \mathrm{Cc}$ & $85,0 \mathrm{Bb}$ & 96,0 Aa \\
\hline & Malva & $75,0 \mathrm{Ac}$ & $89,0 \mathrm{Ab}$ & $94,0 \mathrm{Aa}$ & $95,0 \mathrm{Aa}$ & $97,0 \mathrm{Aa}$ \\
\hline \multirow{4}{*}{ IVG } & Mata-pasto & $13,11 \mathrm{Ce}$ & $17,27 \mathrm{Bd}$ & $25,43 \mathrm{Bc}$ & $31,01 \mathrm{Bb}$ & $38,90 \mathrm{Ca}$ \\
\hline & Malícia & $0,0 \mathrm{Dd}$ & 7,90Cc & $8,13 \mathrm{Dc}$ & $17,24 \mathrm{Cb}$ & $28,38 \mathrm{Da}$ \\
\hline & Fedegoso & $6,50 \mathrm{Bd}$ & $9,70 \mathrm{Cd}$ & $16,30 \mathrm{Cc}$ & $31,57 \mathrm{Bb}$ & $53,93 \mathrm{Ba}$ \\
\hline & Malva & $37,10 \mathrm{Ac}$ & 43,33Aab & $45,33 \mathrm{Aa}$ & $46,60 \mathrm{Aa}$ & $47,10 \mathrm{Aa}$ \\
\hline
\end{tabular}

Médias seguidas de letras iguais, minúsculas na linha e maiúsculas na coluna, dentro de cada parâmetro analisado, não diferem pelo teste de Tukey $(5 \%)$. 
inibições observadas. Com o aumento da densidade, há menor disponibilidade das substâncias para as sementes, diminuindo, conseqüentemente, a quantidade total de substâncias absorvidas por semente, deixando de atingir o nivel requerido para promover inibições. Esse aspecto foi mais relevante para sementes grandes do que para pequenas, que requerem menor volume de substância a ser absorvida.

As sementes constituem-se em importante veículo de suprimento de novos indivíduos de plantas daninhas em áreas de pastagens cultivadas. Esse aspecto torna-se fator complicador quando se sabe da extrema capacidade que essas plantas possuem para produzir sementes (Lorenzi, 1991). Deuber (1992) listou uma série de bons exemplos do potencial de produção de sementes de espécies de plantas daninhas, com: Amaranthus spp. -120.000, Solanum americanum - 178.000 e Sonchus oleracens -400.000 sementes por planta por ano. Considerando que neste trabalho os efeitos potencialmente alelopáticos variaram em função do número de sementes $\mathrm{m}^{-2}$, o conhecimento das espécies que compõem o estrato herbáceo, assim como do potencial de produção de sementes, é importante instrumento a ser considerado em estudos de campo, visando a avaliação da atividade biológica de substâncias químicas, com atividade alelopática.

\section{Variações na atividade potencialmente alelopática da parte aérea e de raízes em função da idade de crescimento}

As variações na atividade alelopática das plantas, bem como o padrão de distribuição em função da idade de crescimento, merecem especial atenção, tendo em vista a possibilidade de estabelecer mecanismos de manejo visando potencializar seus efeitos sobre plantas daninhas em áreas de pastagens cultivadas. Os resultados obtidos neste trabalho mostram que as inibições médias promovidas pelos extratos preparados a partir das raízes e da parte aérea (folhas+colmos) do calopogônio variaram em função da espécie receptora, da idade de crescimento das plantas e da parte da planta utilizada no preparo do extrato. Na Figura 1 observa-se que, para idades de 2 a 10 semanas de crescimento, as inibições potencialmente alelopáticas promovidas pela parte aérea do calopogônio foram sempre superiores às promovidas pelo extrato de raízes. No entanto, a diferença tendeu a diminuir com o aumento da idade da planta, e, na idade de 12 semanas de crescimento, a inibição promovida pelo extrato de raízes foi ligeiramente superior àquela proporcionada pelo extrato da parte aérea. Os extratos preparados da parte aérea do calopogônio evidenciaram inibições potencialmente alelopáticas em todas as idades de coleta, embora a intensidade tenha sido reduzida com o aumento da idade, notadamente a partir da oitava semana de crescimento. Já para o extrato preparado de raízes, a atividade inibitória potencialmente alelopática foi extremamente baixa entre as idades de dois a oito semanas de crescimento, havendo, nas idades de 10 e 12 semanas, tendência de aumento na atividade inibitória. Comparativamente, a atividade potencialmente alelopática nas duas frações da planta atingiu valores máximos em diferentes idades de crescimento. No caso da parte aérea, esse valor foi obtido na idade de quatro semanas de crescimento, enquanto para as raizes esse valor foi verificado na idade de 12 semanas.

Compostos com propriedades alelopáticas altamente diversificados quimicamente são comumente encontrados nas plantas superiores, podendo a quantidade e a composição química deles variar com a espécie de planta (Putnam, 1983). Conquanto não se saiba com exatidão o número total de metabólitos produzidos, as estimativas apontam para algo em torno de 400.000 (Bansal \& Ghan, 1993).

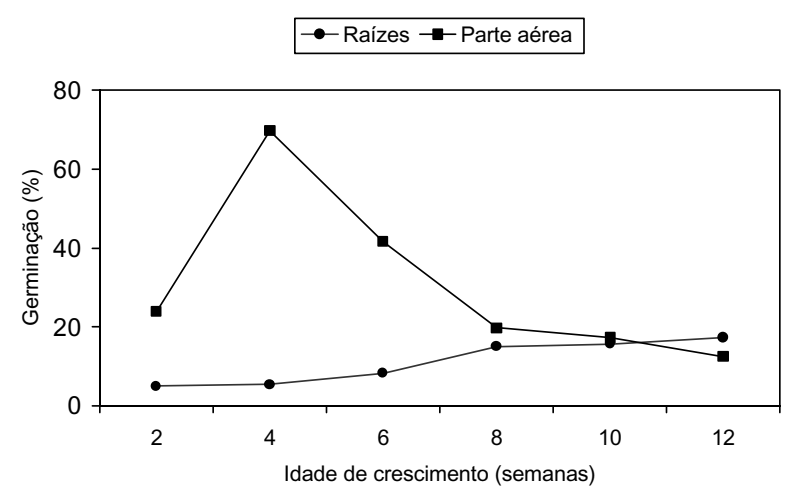

Figura 1 - Variações na atividade potencialmente alelopática em função da idade de crescimento de raízes e parte aérea do calopogônio. Dados expressos em percentual de inibição em relação ao tratamento testemunha (água destilada). 
O padrão de produção e de distribuição de aleloquímicos na planta ainda permanece por ser elucidado. Argandona et al. (1981) mostram que a produção de substâncias químicas com atividade alelopática varia dentro de uma mesma espécie. Esse efeito foi observado no presente trabalho, no qual se verificou que parte aérea e raízes evidenciaram comportamento diferenciado em relação às atividades alelopáticas observadas na parte aérea e nas raízes.

Aparentemente, os compostos secundários das plantas são continuamente sintetizados e degradados na célula, com finalidade específica, e sua sintese obedece a certos preceitos genéticos (Barze \& Horse, 1975). Entretanto, evidências a respeito de variações na produção de aleloquímicos em resposta à maturação são apresentadas por Argandona et al. (1980). Em estudos desenvolvidos com Secale cereale, cultivar Bates, envolvendo a coleta de plantas nas idades de 30, 45, 60 e 75 dias após o plantio, mostrou-se que o maior valor de ácido hidroxâmico foi obtido na idade de 60 dias. No presente trabalho, embora não tenham sido identificadas as substâncias químicas envolvidas na atividade potencialmente alelopática das raízes e da parte aérea do calopogônio, os efeitos alelopáticos variaram em função da idade de crescimento e da parte da planta coletada. Aparentemente, o calopogônio aloca suas substâncias químicas de forma diferenciada na parte aérea e nas raízes; na fase inicial de crescimento, ele aloca, preferencialmente, suas substâncias químicas com atividade alelopática na parte aérea da planta, com o valor máximo sendo atingido na idade de quatro semanas de crescimento. Com o avanço da idade, notadamente a partir da décima semana de crescimento, a planta passa a alocar suas substâncias preferencialmente nas raízes.

Tendo por base os efeitos promovidos pelos extratos sobre a germinação das sementes de cada espécie de planta invasora, verifica-se que, nos extratos aquosos preparados a partir de raízes, os efeitos potencialmente alelopáticos foram extremamente baixos ou inexistentes para a germinação das sementes das espécies malva e mata-pasto (Tabela 2). Apenas a germinação das sementes da planta daninha malícia apresentou inibição acima de $25 \%$, para extratos aquosos preparados de raízes coletadas nas idades de 8 a 12 semanas de crescimento. Para extrato preparado a partir da parte aérea do calopogônio (Tabela 3), a inibição da germinação das sementes da malícia esteve sempre acima dos $50 \%$ para material colhido nas idades de duas $(56,5 \%)$, quatro $(90,5 \%)$ e seis $(62,0 \%)$ semanas de crescimento. Para fedegoso, inibições acima de $50 \%$ foram verificadas para material colhido nas idades de quatro $(78,9 \%)$ e seis $(52,2 \%)$ semanas de crescimento. À semelhança dos resultados observados para os efeitos dos extratos de raízes, mata-pasto e malva foram as espécies em que as inibições foram de menor magnitude, porém inibições da ordem de $56,3 \%$, para mata-pasto, e de $53,6 \%$, para malva, foram verificadas em material colhido na idade de quatro semanas de crescimento (Tabela 3). Esses resultados mostram que, independentemente da fração da planta de onde o extrato foi preparado e da idade de coleta, malícia e fedegoso foram as espécies mais sensiveis aos efeitos potencialmente alelopáticos, ficando mata-pasto e malva como aquelas cuja germinação das sementes foi menos sensivel a esses efeitos.

Considerando a inibição mínima de 50,0\% da germinação como um padrão satisfatório para avaliar as potencialidades alelopáticas de um extrato (Dudai et al., 1999), em nenhuma das seis idades de coleta deste trabalho o extrato aquoso das raízes proporcionou inibição dessa magnitude. Para a parte aérea do calopogônio, apenas na idade de quatro semanas de crescimento inibição dessa ordem foi observada para todas as espécies receptoras. Isso é um indicativo de que nas raízes, em idades de 2 a 12 semanas, a concentração de aleloquímicos está abaixo daquela requerida para promover inibição da germinação da ordem de $50,0 \%$, enquanto na parte aérea apenas na idade de quatro semanas isso é verificado.

A análise conjunta das informações obtidas neste trabalho deixa claro que as plantas de calopogônio alocam suas substâncias químicas com atividades potencialmente alelopáticas, preferencialmente, na parte aérea nas fases iniciais de crescimento, o que pode ser explicado pela necessidade de sobrevivência, passando, com o avanço da idade, a alocar essas substâncias nas raízes. Esse aspecto é de grande importância, pois revela a possibilidade de implementar estratégias de manejo com 
Tabela 2 - Efeitos da idade de crescimento na atividade potencialmente alelopática das raízes do calopogônio. Dados expressos em percentual de inibição da germinação em relação ao tratamento testemunha (água destilada)

\begin{tabular}{|l|c|c|c|c|c|c|}
\hline \multirow{2}{*}{ Planta receptora } & \multicolumn{7}{|c|}{ Idade de coleta de raízes (em semanas) } \\
\cline { 2 - 7 } & 2 & 4 & 6 & 8 & \multicolumn{1}{c|}{10} & 12 \\
\hline Mata-pasto & $5,4 \mathrm{Ba}$ & $3,2 \mathrm{Cb}$ & $2,2 \mathrm{Cc}$ & $5,4 \mathrm{Da}$ & $3,2 \mathrm{Db}$ & $3,2 \mathrm{Db}$ \\
Malva & $4,2 \mathrm{Cd}$ & $4,2 \mathrm{Bd}$ & $3,3 \mathrm{Cd}$ & $7,2 \mathrm{Cc}$ & $17,5 \mathrm{Ba}$ & $12,4 \mathrm{Cb}$ \\
Malícia & $8,1 \mathrm{Ae}$ & $9,6 \mathrm{Ad}$ & $17,4 \mathrm{Ac}$ & $27,6 \mathrm{Ab}$ & $27,8 \mathrm{Ab}$ & $30,6 \mathrm{Aa}$ \\
Fedegoso & $2,2 \mathrm{Df}$ & $4,4 \mathrm{Be}$ & $10,1 \mathrm{Bd}$ & $20,0 \mathrm{Bb}$ & $14,4 \mathrm{Cc}$ & $23,1 \mathrm{Ba}$ \\
\hline
\end{tabular}

Médias seguidas de letras iguais, maiúsculas na coluna e minúsculas na linha, não diferem pelo teste de Tukey $(0,05)$.

Tabela 3 - Efeitos da idade de crescimento na atividade potencialmente alelopática da parte aérea do calopogônio. Dados expressos em percentual de inibição da germinação em relação ao tratamento testemunha (água destilada)

\begin{tabular}{|l|c|c|c|c|c|c|}
\hline \multirow{2}{*}{ Planta receptora } & \multicolumn{6}{|c|}{ Idade de coleta da parte aérea (em semanas) } \\
\cline { 2 - 7 } & 2 & 4 & 6 & 8 & 10 & 12 \\
\hline Mata-pasto & $6,5 \mathrm{Cd}$ & $56,3 \mathrm{Da}$ & $19,4 \mathrm{Db}$ & $7,5 \mathrm{Cd}$ & $9,7 \mathrm{Dc}$ & $3,2 \mathrm{De}$ \\
Malva & $7,2 \mathrm{Cd}$ & $53,6 \mathrm{Ca}$ & $32,9 \mathrm{Cb}$ & $7,2 \mathrm{Cd}$ & $11,3 \mathrm{Cc}$ & $7,2 \mathrm{Cd}$ \\
Malícia & $56,5 \mathrm{Ac}$ & $90,5 \mathrm{Aa}$ & $62,0 \mathrm{Ab}$ & $45,6 \mathrm{Ad}$ & $30,4 \mathrm{Ae}$ & $21,7 \mathrm{Af}$ \\
Fedegoso & $25,6 \mathrm{Bc}$ & $78,9 \mathrm{Ba}$ & $52,2 \mathrm{Bb}$ & $18,9 \mathrm{Bd}$ & $17,8 \mathrm{Bd}$ & $17,8 \mathrm{Bd}$ \\
\hline
\end{tabular}

Médias seguidas de letras iguais, maiúsculas na coluna e minúsculas na linha, não diferem pelo teste de Tukey $(0,05)$.

vistas à maximização dos efeitos potencialmente alelopáticos do calopogônio em condições de pastagens cultivadas consorciadas com essa leguminosa e, dessa maneira, reduzir a competição com as plantas daninhas. Pelos resultados, devem-se utilizar manejos que possibilitem manter essa leguminosa forrageira em idade de quatro semanas de crescimento, quando as plantas alocam maiores quantidades de substâncias químicas com atividade potencialmente alelopática na parte aérea.

\section{LITERATURA CITADA}

ARGANDONA, V. H.; NIEMEYER, H. M.; CORCUERA, L. J. Effects of content and distribuition of hidroxamic acids in wheat on infested by the aphyd. Schizaphis graminum. Phytochemistry, v. 20, p. 673-676, 1981.

ARGANDONA, V. H. et al. Role of hidroxamic acids in the resistence of cereals to aphides. Phytochemistry, v. 19, p. $1665-1668,1980$.

BANSAL, G. L.; GHAN, V. W. Status of research on allelopathy and future scop of work in Indian. Ind. J. Agric. Sci., v. 63, n. 12, p. 769-776, 1993.

BARZE, W.; HORSE, W. Metabolism of flavonoids. In: HARBONE, J.B. (Ed.). The flavonoids. London: Chapman \& Hall, 1975. p. 916-969.
BRADOW, J. M.; CONNICK, W. J. Volatile seed germination inhibitor from plant residues. J. Chem. Ecol., v. 16, p. 645-666, 1990.

DEUBER, R. Ciências das plantas daninhas: fundamentos. Jaboticabal: FUNEP, 1992. v. 1. 413 p.

DUDAI, N. et al. Essencial oils as allelochemicals and their potential use as bioerbicides. J. Chem. Ecol., v. 25, n. 5, p.H1079-1089, 1999.

DURAM, R. D.; TORTOSA, M. E. The effect of mechanical and chemical scarification on germination of charlock (Sinapis arvensis L.) seeds. Seed Sci. Technol., v. 13, n. 1, p. 155-163, 1985.

EINHELLIG, F. A. Plant x plant allelopathy: biosynthesis and mechanism of action. In: CONGRESSO BRASILEIRO DE FISIOLOGIA VEGETAL, 5., 1995, Lavras, MG. Anais... Lavras: SBFV, 1995. p. 133-147.

FRIEDMAN, J.; WALLER, G. R. Seeds as allelopathic agents. J. Chem. Ecol., v. 9, p. 1107-1117, 1983.

HEDGE, R. S.; MILLER, D. A. Allelopathy and autotpxicity in alfafa characterization and effects of preceding crops and residue. Crop Sci., v. 30, p. 12551259, 1990.

JUNTILA, O. Seed and embryo germination in S. vulgaris and $S$. reflexas as affecyed by temperature during seed development. Physiol. Plant., v. 29, p. 264-268, 1976.

Planta Daninha, Viçosa-MG, v.21, n.2, p.211-218, 2003 
LANGENHEIM, J. H. Higher plant terpenoids: a phytocentric overview of their ecological roles. J. Chem. Ecol., v. 20, n. 6, p. 1223-1282, 1994.

LORENZI, H. Plantas daninhas do Brasil. Terrestres, aquáticas, parasitas, tóxicas e medicinais. Nova Odessa: Plantarum, 1991. $440 \mathrm{p}$

PUTNAM, A. R. Allelopathy; a break in weed control? Am. Fruit Grower, v. 103, n. 6, p. 10, 1983.

PUTNAM, A. R.; DeFRANK, J. Use of allelopathy cover to inhibit weeds. In: CONGRESS PLANT PROT, 1981, Mineapolis. Proceedings... Mineapolis: 1981. p.508-582.

RAO, A. S. Roots flavonoids. Bot. Rev., v. 56, n. 1, p. $1-55,1990$.

RICE, E. L. Allelopathy: an overview. In: WALLER, G.R. Allelochemical role in agriculture and forestry. Washington, D.C.: American Chemical Society, 1987. p. 7-22. (ACS. Symposium Series, 330).

SAS- INSTITUTE . Statistical Analysis System. User's Guide. Version 6. 4.ed. Cary: 1989. 846 p.

SMITH, A. E.; MARTIN, D. L. Allelopathic characteristics of three cool-season grass in the forage ecosystems. Agron. J., v. 8, n. 2, p. 243-246, 1994.

SOUZA FILHO, A. P. S. Potencialidades alelopáticas envolvendo gramíneas e leguminosas forrageiras e plantas invasoras de pastagens. $1995.137 \mathrm{f}$. Tese (Doutorado em Zootecnia) - Universidade Estadual Paulista, Jaboticabal, 1995.
SOUZA FILHO, A. P. S.; ALVES, S. M.; DUTRA, S Variações na atividade potencialmente alelopática do capimmarandu em função do estádio de desenvolvimento das plantas. In: REUNIÃO ANUAL DA SOCIEDADE BRASILEIRA DE ZOOTECNIA, 37., 2000, Viçosa, MG. Anais ...Viçosa: SBZ, 2000. CD-ROM.

SOUZA FILHO, A. P. S.; DUTRA, S.; SILVA, M. A. M. M. Métodos de superação da dormência de sementes de plantas daninhas de pastagens cultivadas da Amazônia. Planta Daninha, v. 16, n. 1, p. 3-11, 1998.

SOUZA FILHO, A. P. S.; RODRIGUES, L. R. A.; RODRIGUES, T. J. D. Efeitos do potencial alelopático de três leguminosas forrageiras sobre três invasoras de pastagens. Pesq. Agropec. Bras., v. 32, n. 2, p. 165-170, 1997a.

SOUZA FILHO, A. P. S.; RODRIGUES, L. R. A.; RODRIGUES, T. J. D. Potencial alelopático de forrageiras tropicais: efeitos sobre invasoras de pastagens. Planta Daninha, v. 15, n. 1, p. 53-60, 1997 b.

WARDLE, D. A. Allelopahtic in New Zealand pasture grassland ecosystem. New Z. J. Exper. Agric., v. 15, p. 243-255, 1987.

WARDLE, D. A.; AHMED, M.; NICHOLSON, K. S. Allelopathy influence of nodding thgistle (Carduus nutans L.) seeds on germination and growth of pasture plants. New Z. J. Agric. Res., v. 34, n. 2, p. 185-191, 1991. 